\title{
EVALUATION OF A MOBILE PEER-EVALUATION SYSTEM FOR IN-CLASS PRESENTATIONS
}

\author{
Peter Gobel and Makimi Kano \\ Kyoto Sangyo University, Japan
}

\begin{abstract}
Simultaneous in-class presentations are well suited to the use of peer evaluation, which also promotes greater involvement of the student audience. The problem for the teacher is how to manage peer evaluation and make it a useful part of the curriculum. PeerEval is a mobile application that allows students to anonymously evaluate presentations in real time using a Likert scale rubric and individual peer comments. The results of each evaluation are compiled in a database which is available to the teacher and the students. This short paper focuses on implementing and evaluating this app in Japanese university classrooms. The researchers sought to evaluate both the technical aspects of the software and nature of student feedback using the software. Student attitudes towards the PeerEval system were measured using a twelve-item questionnaire concerning usability of the software, their attitudes towards the system both as a presenter and as an audience member. Results are discussed regarding student perceptions of the evaluation system, overall feedback quality, and the perceived effect of feedback speed and peer comments. Further uses for a mobile peer-evaluation system are also discussed.
\end{abstract}

\section{KEYWORDS}

Peer Evaluation, Active Learning, Higher Education, Mobile Assisted Language Learning

\section{INTRODUCTION}

PeerEval (https://peereval.mobi/) is a peer evaluation application developed to be used with simultaneous in-class presentations. These kinds of presentations have a number of positive benefits, such as reducing speaking anxiety and promoting greater involvement of the students in the presentations (Cote, 2013). PeerEval seeks to deal with a number of drawbacks to current forms of peer evaluation such as, considerable paperwork, a reluctance to fairly evaluate peers or comment critically, and asynchronous rating.

This short paper gives an explanation of the development of the PeerEval system, a description of the use of the app, and a user evaluation of the software. Student attitudes towards PeerEval were measured using a twelve-item questionnaire concerning usability of the software and their attitudes towards the system as a presenter and as an audience member.

\section{PEER EVALUATION OF PRESENTATIONS}

Modern teaching practices such as poster presentations have allowed for more active learning by giving students more performance time in language classrooms. One of the drawbacks with such activities is that the teacher must, by the very nature of the activity, play a smaller role. It is almost impossible for the teacher to evaluate all students in such an activity. This situation leads to the implementation of some sort of peer evaluation. With proper planning and careful execution, peer evaluation can have a positive effect on both performance and L2 acquisition (Hansen \& Liu, 2005; Gobel \& Kano, 2017).

Peer assessment has been used as an alternative evaluation method for a variety of oral presentation activities (Boud, Cohen \& Sampson, 1999; Patri, 2002; Shimura, 2006). It can encourage active involvement of the students, foster collaborative learning, and contribute to learner autonomy (Donato, 1994; Kessler \& Bikowski, 2010; Rust, Price, \& O’Donovan, 2003; Tseng \& Tsai, 2010). 
With the above benefits in mind, many teachers and textbooks have created paper-based rubrics for peer evaluation. While these paper-based assessment forms are useful, they pose a number of problems. One problem is the issue of anonymity. Without some privacy and anonymity, the effect of social influence may increase (Panadero, Romero, \& Strijbos, 2013; Tseng, et al., 2010). In addition to this, collating paper evaluations is a time-consuming task.

Some of these problems can be alleviated by using LMS such as Moodle or Blackboard, which make it easy for students to input scores online and for the teacher to manage these scores. Such systems have been used to great effect in the peer assessment of writing (see Davies, 2000, for an overview). But it is still difficult to ensure total anonymity of feedback and comments on a forum. Some research has been done with classroom response technologies (CRT) and anonymity (Bojinova and Oigara, 2011, 2013; Raes, Vanderhoven., \& Schellens, 2013), but these dealt with simple assessment scores, as opposed to written feedback. Also, CRT assessment is usually done asynchronously.

To solve these problems, PeerEval was created with a simple interface that is both flexible and anonymous in nature. The application sought to create evaluation rubrics that could be used quickly and anonymously to give quick and accurate impressions to their peers, as well as giving users immediate access to their scores and feedback. The following section describes the PeerEval system and how it has been used for in-class presentations and peer assessment.

\subsection{Description of the System}

There are two components: a browser-based system for the instructor to create the evaluation criteria, to upload the student name list, and to download the results; and the iOS app that the students use for their assessments. In addition, from 2018 students can access the PeerEval student system (the same as the app) on any web browser.

Teachers need to go to http://peereval.mobi, where there are two choices. Teachers may use the system without registration, but they must configure their session, conduct their class and download their results within a set time period. Teachers with login-access can create multiple rubrics, sessions and classes that remain in the system until the teacher elects to delete them.

Teachers create a session by naming the session, inputting student information and choosing or creating a rubric. Student information can be input on the webpage itself or by uploading a .csv file with all the relevant information.

Within PeerEval, teachers can choose one of the default rubrics or create their own. A set of up to six rubrics can be set up for one session, with a choice of four-point or five-point Likert scales. Each rubric consists of a title for the item, a description of the item, and a 4-5 point Likert scale (see Figure 1).

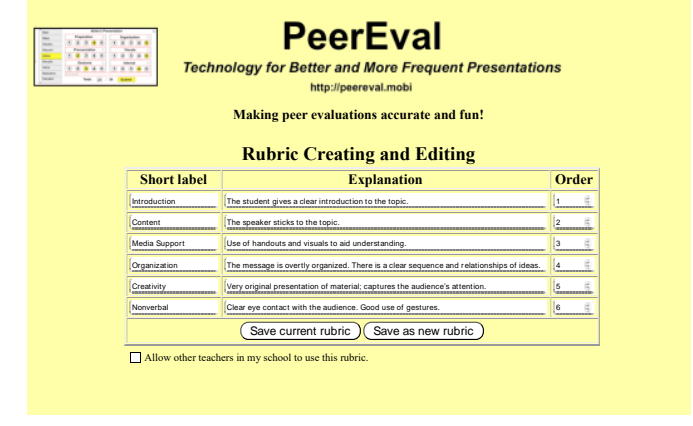

Figure 1. Rubric set up

Once a session has been fully set up, an access code is created which will be used by the students, along with their handle to access the session via the app.

Once a session has been completed, the teacher can view or download the results. The teacher can show the results instantly on the class screen if s/he is not concerned about student privacy, or print them out and supply the students with their own scores, which also show the class averages (Figure 2). 


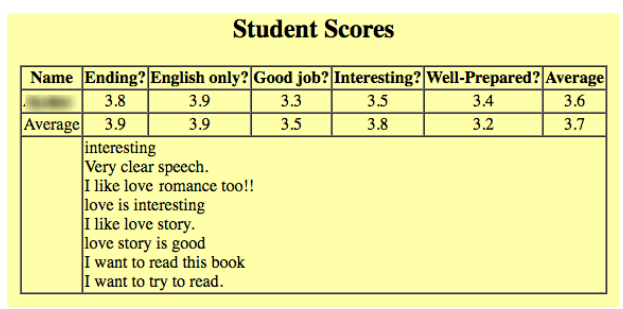

Figure 2. Individual score report

\subsubsection{Student Attitudes towards the PeerEval App}

To informally measure student attitudes towards PeerEval, a twelve-item questionnaire was created addressing affective, practical, and technical issues (Chen, 2014), and administered to students who had experience with both paper-based and PeerEval peer evaluation procedures. The rubrics for both procedures were similar. The questionnaire was divided into five questions about the PeerEval app itself, three questions comparing paper-based and app-based evaluation from the presenter's point of view, and four questions comparing paper and app-based evaluation from the point of view of the audience. The questionnaire was administered to a total of 39 students, enrolled in four separate classes. In all four classes, the students first gave short presentations and were graded using a paper-based rubric. In the following month, they gave a separate presentation and were evaluated on a similar rubric via PeerEval. Cronbach's alpha for the results was .73, indicating acceptable but weak internal consistency.

Table 1 shows the result of the questionnaire. As for Items 1-5, a 4-point Likert scale was used, 1 being "Agree," and 5 being "Don't agree." As for Items 6-12, a 4-point Likert scale was used, 1 being the strong preference to paper-based evaluation, and 4 being strong preference to the app-based evaluation. In general, students felt that the app was easy to install and use (Items 1-5). They felt that the evaluation system was clear and that the comments and feedback would help them prepare more for subsequent presentations. From the presenters' standpoint, the feedback speed was a major plus, and the ability to quickly read peer comments was viewed as helpful (Items 6-7). From the point of view of the audience, everyone preferred the privacy and feedback speed of the app and felt that the app gave them the feeling that the presentations were more interactive (Item 12). The students also felt that the app allowed them to evaluate more accurately than using paper-based methods (Items 9-11).

Table 1. Questionnaire Results

\begin{tabular}{|c|r|r|r|r|r|r|r|r|r|r|r|r|}
\hline & Q1 & Q2 & Q3 & Q4 & Q5 & Q6 & Q7 & Q8 & Q9 & Q10 & Q11 & Q12 \\
\hline Mean & 1.76 & 1.72 & 1.92 & 2.00 & 1.75 & 3.6 & 2.96 & 2.48 & 3.64 & 3.48 & 3.12 & 2.96 \\
\hline Mode & 1 & 1 & 1 & 1 & 1 & 4 & 4 & 1 & 4 & 4 & 4 & 3 \\
\hline
\end{tabular}

The preliminary results of comparing PeerEval with paper-based forms of peer evaluation allowed us to consider student preferences. Students generally had a favorable impression of the system, but presenters felt audience members were paying less attention to presentations and more attention to their phones. This preliminary result suggests that rules and/or procedures should be put into place regarding when students are allowed to input their evaluations.

\section{CONCLUSION}

This paper briefly described a peer assessment mobile app, how it is used in context, and student attitudes towards the use of the app in reference to a paper-based rubric. The results of this preliminary study suggest that PeerEval-generated interaction quality and quantity may be different from asynchronous peer feedback.

Although PeerEval was designed to overcome rating problems with paper and LMS-based forms of peer evaluation, the present study only compared students' perceptions of paper-based and PeerEval peer evaluation procedures, without collecting data about LMS-based peer evaluation. In addition, previous studies have shown a positive effect of training in technology-based peer evaluation (Ho \& Savignon, 2007) suggesting that more detailed feedback training will produce more useful, helpful, and relevant comments. 


\section{ACKNOWLEDGEMENT}

The authors would like to thank the developers of the app.

\section{REFERENCES}

Bojinova, E., \& Oigara, J., 2011. Teaching and learning with clickers: Are clickers good for students? Interdisciplinary Journal of E-Learning and Learning Objects, 7, 169-184. Retrieved from http://www.ijello.org/Volume7/IJELLOv7p169-184Bojinova772.pdf

Bojinova, E., \& Oigara, J., 2013. Teaching and learning with clickers in higher education. International Journal of Teaching and Learning in Higher Education, 25(2), 154-165. Retrieved from https://files.eric.ed.gov/fulltext/EJ1016407.pdf

Boud, D., Cohen, R., \& Sampson, J., 1999. Peer learning and assessment. Assessment and Evaluation in Higher Education, 24(4), 413-26. doi:10.1080/0260293990240405

Chen, T., 2014. Technology-supported peer feedback in ESL/ EFL writing classes: a research synthesis, Computer Assisted Language Learning, DOI: 10.1080/09588221.2014.960942

Cote, R., 2013. The role of student attitude towards peer review in anonymous electronic peer review in an EFL writing classroom. Unpublished Ph.D. Dissertation Retrieved http://arizona.openrepository.com/arizona/bitstream/10150/307005/3/azu_etd_13017_sip1_m.pdf

Davies, P., 2000. Computerized peer assessment. Innovations in Education and Training International, 37(4), 346-355, doi:10.1080/135580000750052955

Donato, R., 1994. Collective scaffolding in second language learning. In J.P. Lantolf, \& G. appel (Eds.), Vygotskian approaches to second language research (pp. 3356). Norwood, NJ: Ablex.

Gobel, P. \& Kano, M., 2017. The complexities of digital storytelling: Factors affecting performance, production, and project completion. In Issa, T., Issa, T., Kommers, P., Isaias, P., \& Issa, T. (Eds.), Smart technology applications in business environments (pp. 343-360). Hershey, PA: IGI Global. doi:10.4018/978-1-5225-2492-2

Hansen, J.G., \& Liu, J., 2005. Guiding principles for effective peer response. ELT Journal, 59(1), 31-39, doi:10.1093/elt/cci004

Ho, M., \& Savignon, S.J., 2007. Face-to-face and computer-mediated peer review in EFL writing. CALICO Journal, 24(2), 269290.

Kessler, G., \& Bikowski, D., 2010. Developing collaborative autonomous learning abilities in computer mediated language learning: Attention to meaning among students in wiki space. Computer Assisted Language Learning, 23(1), 4158.

Panadero, E., Romero, M., \& Strijbos, J. W., 2013. The impact of a rubric and friendship on peer assessment: Effects on construct validity, performance, and perceptions of fairness and comfort. Studies in Educational Evaluation, 39(4), 195-203. doi:10.1016/j.stueduc.2013.10.005

Patri, M., 2002. The influence of peer feedback on self and peer-assessment of oral skills. Language Testing, 19, 109-131. doi: 10.1191/02655322021t224oa

Raes, A., Vanderhoven, E., \& Schellens, T., 2015. Increasing anonymity in peer assessment by using classroom response technology within face-to-face higher education. Studies in Higher Education, 40(1), 178-193. doi:10.1080/03075079.2013.823930.

Rust, C., Price, M., \& O’Donovan, B., 2003. Improving students' learning by developing their understanding of assessment criteria and processes. Assessment and Evaluation in Higher Education, 28(2), 147-164. doi:10.1080/02602930301671

Shimura, M., 2006. Peer-and instructor assessment of oral presentations in Japanese university EFL classrooms: A pilot study. Waseda Global Forum, 3, 99-107.

Tseng, S. C., \& Tsai, C. C., 2010. Taiwan college students' self-efficacy and motivation of learning in online peer assessment environments. The Internet and Higher Education, 13(3), 164-169. Retrieved from https://www.learntechlib.org/p/108386/. 